\title{
Work-related stress in a humanitarian context: a qualitative investigation
}

\author{
Liza Jachens Research Associate and Lecturer, Psychology, Sociology and \\ Professional Counseling Faculty, Webster University, Switzerland, Jonathan
} Houdmont Assistant Professor of Occupational Health Psychology, Division of Psychiatry and Applied Psychology, School of Medicine, University of Nottingham, United Kingdom, and Roslyn Thomas Associate Professor, Psychology, Sociology and Professional Counseling Faculty, Webster University, Switzerland

There is a paucity of research on the subjective stress-related experiences of humanitarian aid workers. Most evaluations of stress among these individuals focus on trauma and related conditions or adopt a quantitative approach. This interview-based study explored how 58 humanitarian aid workers employed by a United Nations-aligned organisation perceived the transactional stress process. The thematic analysis revealed eight main topics of interest: an emergency culture was found where most employees felt compelled to offer an immediate response to humanitarian needs; employees identified strongly with humanitarian goals and reported a high level of engagement; the rewards of humanitarian work were perceived as motivating and meaning ful; constant change and urgent demands resulted in work overload; and managing work-life boundaries and receiving positive support from colleagues and managers helped to buffer perceived stress, work overload, and negative health outcomes. The practical implications of the results are discussed and suggestions made in the light of current research and stress theory.

Keywords: humanitarian aid worker, qualitative interviews, work-related stress, health, well-being

\section{Introduction}

Humanitarian aid workers (HAWs) are critical to efforts to assist the world's most vulnerable populations and to the attainment of global health goals. The context in which the humanitarian community works is constantly evolving; disease outbreaks, natural disasters, and political instability, inter alia, require swift adaptation to changing environments. HAWs are likely to be best prepared for these challenges when their own psychological health and well-being are optimal. It has been established, though, that HAWs are at increased risk in relation to various undesirable states, including anxiety, burnout, depression, and post-traumatic stress disorder (Cardozo et al., 2005; Connorton et al., 20I I; Ager et al., 2012), as well as hazardous levels of alcohol consumption (Jachens, Houdmont, and Thomas, 20I6).

The literature concerned with stress among HAWs concentrates principally on traumatic or acute stress and humanitarian aid work as a risk factor for traumarelated mental illness (Connorton et al., 2012). However, a number of investigations 
into human service occupations have highlighted the importance of measuring both the experiences of trauma and more frequently experienced minor organisational stressors (that is, daily hassles) (Brown, Fielding, and Grover, I999; Brough, 2002; Hart and Cotton, 2003). Chronic stress often is a result of regular exposure to organisational stressors, defined as 'the niggling aspects of the work environment' that pervade organisations because of the 'structural arrangements and social life' within them (Shane, 20I0, p. 8I5). Studies have shown repeatedly that it is the organisational aspects of emergency service work, such as firefighting and policing, rather than the operational dimensions that employees perceive as the primary sources of stress and that are most strongly linked to negative outcomes (Brough, 2004; Houdmont, 20I7). Furthermore, many humanitarian organisations fail to provide hands-on training with respect to stress management and have limited awareness of the role of bureaucratic and organisational actions in managing stress (Ehrenreich and Elliott, 2004).

The occupational health literature has consistently revealed that workplace characteristics concerned with the design, management, and organisation of work-so-called psychosocial hazards - may influence workers' health and well-being (Sverke, Hellgren, and Näswall, 2002; Stansfeld and Candy, 2006; Bonde, 2008; Schütte et al., 2014). Furthermore, psychosocial hazard exposure is linked to important organisational health outcomes such as absenteeism, burnout, and diminished performance quality (Manning and Preston, 2003).

Psychosocial risk research is lacking in the peer-reviewed humanitarian literature and yet humanitarian agencies are increasingly concerned about the impact of stress on the effectiveness and efficiency of service delivery (Welton-Mitchell, 20I3). Although there are likely to be commonalities across occupations in terms of the prevalent psychosocial hazards, many will also encompass stressors that are unique to particular realms (Blase, I986; Narayanan, Menon, and Spector, I999; Lindsay, Taylor, and Shelley, 2008). Furthermore, there are likely to be role-specific stressors within occupations. These are important distinctions because there is evidence to suggest that role-specific stressors may contribute separately from generic stressors to the generation of stress-related outcomes (Noblet et al., 2005; Pryjmachuk and Richards, 2007; Brough and Biggs, 2015). Given these omissions in the psychosocial risk literature as it relates to humanitarian contexts, further research in this area is timely.

Conventionally, a multidimensional concept such as stress has been measured either using a set of indicators or a composite index (Durand, 20I5). This approach is particularly useful for making comparisons across organisations and countries. However, quantitative methods have some limitations: 'applying only quantitative methods is likely to overlook important variables or the context in which some phenomenon might or might not occur. Even in mature areas, the exclusive use of quantitative approaches risks too narrow a focus, failing to consider alternative explanations and important contextual variables' (Spector and Pindek, 20I5, p. I3). Where researchers rely on psychometrically valid measurement tools, their assumption rests on the appraisal of relevant psychosocial hazards (Beiske, 2002). This may lead to the neglect of a wide variety of variables that are meaningful for the population under 
review (Creswell et al., 2003; Mazzola, Schonfeld, and Spector, 20I i; Schonfeld and Mazzola, 20I2; Ritchie et al., 20I3). The intensity of exposure to psychosocial hazards and relations between them may also be unobserved. In addition, studies confirm a lack of inquiries into psychosocial work factors other than those conceptualised by single models or theories (Bonde, 2008; Netterstrøm et al., 2008).

In response to these limitations in the literature, this study adopts a transactional theoretical perspective that conceptualises work-related stress as a process composed of three elements: antecedent factors, namely exposure to psychosocial hazards (also referred to herein as stressors); cognitive perceptual processes that give rise to the emotional experience of stress; and correlates of that experience, both individual (such as physical and psychological health outcomes and health risk behaviours) and organisational (such as absenteeism, organisational commitment and morale, and performance) (Cox and Griffiths, 20I0).

The study used qualitative interviews to answer the following question: how is the work-related stress process perceived among humanitarian aid workers? The aim of the evaluation is to provide the humanitarian sector and allied professions with insights into the persistent psychosocial problems faced by employees. It is hoped that the common dynamics and patterns of interaction within the organisation, and particularly those that employees find problematic, may be brought to conscious attention and stimulate reflection, discussion, and action. The development of a healthy and engaged workforce maintained through evidence-based organisational policies and practices will facilitate the achievement of the humanitarian mandate.

\section{Methodology}

\section{Participants and procedure}

Participants ( $\mathrm{N}=\mathrm{I}$ I6) were selected first by random sampling from the employee list of a humanitarian organisation based in Geneva, Switzerland, with a mandate to promote health and well-being among the world's vulnerable populations. This initial sample (20 per cent of the organisation) was considered large enough to allow for anticipated non-responses while capturing data on the full range of experiences. Selected employees were sent detailed information about the study by e-mail. Subsequently, each received a telephone call inviting them to participate in a faceto-face interview (20 could not be reached by telephone). A total of 58 employees (28 men, 30 women) agreed to take part, representing Io per cent of the organisation's workforce. Of the interviewees, approximately one-third were from senior, middle, and lower grades, respectively. The mean age was 4I (range 25-6I) and their job experience ranged from I-34 years $(\mathrm{M}$ (mean) $=\mathrm{I}$ I, SD (standard deviation $)=8.54$ years). All employees were based in Geneva at the time of the study but many regularly travelled abroad on business. The reasons cited for not contributing to the study were: parental leave, travel, illness, lack of interest, or too busy $(n=30)$. There were eight 'no shows' for the scheduled interviews. 
The study had Institutional Review Board (IRB) ethics approval. Before commencing with the interviews, the objectives of the study, the voluntary nature of participation (as well as the right to withdraw without justification), and issues pertaining to anonymity and confidentiality of the data were explained. Participants signed a consent form and permission for the audio taping of the interviews was obtained. Sources of support were signposted in case the interview raised issues that participants might wish to discuss further.

\section{Semi-structured interview}

A semi-structured interview comprising I2 questions was used to elicit information from participants on their experience of the transactional stress process. Previous research (Bhui et al., 20I6), theoretical stress models (Siegrist, I996), and key organisational concerns (such as absenteeism rates) guided the development of the interview questions. The topics covered were: work demands/efforts; rewards; job characteristics; and perceived stress and social support. The questions were piloted on four employees who had experienced work-related stress. The content of these pilot interviews was used to refine the topics and to gather feedback from participants on the clarity and appropriateness of the questions. Probing techniques were applied to draw out additional information on matters of importance and to provide the basis for comparison (Bernard, 20I2). Liza Jachens and Roslyn Thomas each conducted an equal number of interviews; these were audio recorded, lasted between 30 and 45 minutes, and took place in a private meeting room at the organisation's premises in Geneva. They also transcribed the audio recordings.

\section{Analysis}

A phenomenological approach was taken to examine the narratives conveyed in the transcripts with a view to guiding an emergent understanding of the perceptions, perspectives, and understandings of HAWs concerning work-related stress (Starks and Trinidad, 2007). For the analysis to be replicable and transparent, the guidelines for thematic analysis set out by Braun and Clarke (2006) were followed. Thematic analysis was used to describe and analyse themes and patterns grounded in the data. An inductive approach was deemed appropriate owing to the exploratory nature of the investigation, allowing for the emergence of unexpected themes (Braun and Clarke, 2006). The data are not intended to underpin assertions regarding generalisability, but rather to suggest insights.

Transcripts were first read and reread and initial interpretations were summarised. Codes were generated and collated into prospective themes that were then reviewed and named. At least Io participants (I7 per cent of sample) were required to comment on an issue for it to be considered as a theme. Two coders were used not only to achieve inter-rater reliability, but also to expose disagreements, a critical process in refining a coding frame (Malterud, 200I). Lastly, an experienced humanitarian professional was consulted to review all of the transcripts and to consider the credibility of the findings. 


\section{Findings}

The thematic analysis of interview transcripts highlighted eight main topics of interest (see Table I):

- emergency culture;

- rewards of humanitarian work;

- constant change;

- high engagement;

- work overload;

- managing work-life boundaries;

- social support; and

- health outcomes.

These themes are illustrated below by quotations extracted from the interview transcripts in line with the methodology of directly expressing the lived experience. One should note that minor modifications were made to some quotes to preserve anonymity.

\section{Emergency culture}

Some employees explained how humanitarian goals and the work context affected their experience of stress. They highlighted how the organisation has to negotiate the demands and complexity of external expectations and 'the disease burden':

Table 1. Work-related stress themes of humanitarian aid workers

\begin{tabular}{|l|l|}
\hline Theme & Description \\
\hline Emergency culture & $\begin{array}{l}\text { The organisation was seen as functioning in 'emergency mode' and there was } \\
\text { a sense of ongoing urgency/crisis. }\end{array}$ \\
\hline Rewards of humanitarian work & $\begin{array}{l}\text { Employees were passionate about and felt rewarded by humanitarian work. } \\
\text { Fieldwork was important to remain motivated and connected to the work. }\end{array}$ \\
\hline Constant change & $\begin{array}{l}\text { Many employees felt stressed due to continual, rapid, and unpredictable change } \\
\text { in the organisation and its rapid pace. }\end{array}$ \\
\hline High engagement & $\begin{array}{l}\text { Employees expressed a high commitment to the organisation and their work. } \\
\text { In addition, many experienced an inability to withdraw from work owing to a } \\
\text { compelling drive to meet beneficiary needs/humanitarian goals. }\end{array}$ \\
\hline Work overload & $\begin{array}{l}\text { Employees believed that they were expected to undertake unrealistic or unman- } \\
\text { ageable workloads that resulted in stress and negative health outcomes. }\end{array}$ \\
\hline Managing work-life boundaries & $\begin{array}{l}\text { Working long, unsocial, and irregular hours impacted negatively on the work- } \\
\text { home life balance. Work was perceived as all-encompassing. }\end{array}$ \\
\hline Social support & $\begin{array}{l}\text { Supportive relationships were key to managing stress at work. Perceived sup- } \\
\text { port was largely dependent on the qualities of managers. }\end{array}$ \\
\hline Health outcomes & $\begin{array}{l}\text { Stress was strongly linked to work overload, the inability to withdraw from } \\
\text { the demands of work, and to negative mental and physical health outcomes. } \\
\text { Distress took the form of anxiety, burnout, depression, and/or a deterioration } \\
\text { in physical health. }\end{array}$ \\
\hline
\end{tabular}

Source: authors. 
. . . these many external expectations put pressure on the organisation. This creates constant pressure internally to satisfy expectations, sometimes undefined expectations . . . that causes us stress. The challenging aspect is to balance strict internal deadlines and at the same time respond to the multiple demands of external countries. . . I feel we are always in emergency mode.

Operating in a climate of 'everything is urgent' was perceived as stressful. Many employees made reference to 'deadlines and to meeting them with urgency' and the organisation functioning in 'emergency mode' or 'short-term modes of operation', generating a 'constant feeling of crisis within the organisation'. The narratives indicated that this 'emergency mindset' was a deeply embedded and accepted cultural norm in the organisation.

\section{Rewards of humanitarian work}

Many employees valued and 'felt energised' by the experience of travelling to the field where they witnessed 'the positive impact' of their work: 'visiting countries in need keeps me connected and motivated to do the things we all care about'. However, a minority of employees reported 'clocking in and clocking out' and said that they were 'not fully present' and committed at work. Some attributed this to 'sitting here and filling out forms remotely in headquarters. We don't get to see what it is all about'. Another employee added:

When I visit the field I get a tingle of you know, what you are doing matters. But on the whole, on the average day, I don't get that tingle any more. We should all go to the field more often so we don't become bored and disenchanted.

Most people held the mission and mandate in high regard, were passionate about what it represented, and were rewarded by the overall impact the organisation had on the populations it serves. This gave them 'the chance to save lives on a big scale'. They derived meaning from their work by 'seeing the effect of our choices on the beneficiaries'.

\section{Constant change}

Many employees stated that the organisation is in constant evolution in response to the humanitarian context. Some employees celebrated the 'very creative, new innovative stuff' and the 'interesting, global and challenging environment'. They viewed their work as an opportunity to 'change things and build relationships', and responded to 'the short-term results, the speed and the dynamism'. The work environment was seen as presenting diverse opportunities; some embraced the 'ability to influence the direction of the organisation'.

The majority of employees, though, were not comfortable with continuing and unpredictable change in the organisation and its rapid pace. Common reactions were 
anxiety regarding loss of control and interpersonal competition and frustration at the extent of the changes (such as restructuring and new procedures/processes) in recent years:

At this point the organisation is changing and reinventing itself perhaps too fast. We don't seem able to get out of or control this cycle, so I just keep my head down and absorb the change.

People react very defensively if you try to change something. People anticipate something going wrong. Rumours about organisational change can create fears as to the stability of our existing jobs. They cause confusion and stress.

\section{High engagement}

Many employees said that they were highly engaged and deeply committed to the mandate, enabling them to report fulfilment and satisfaction with their work:

I'm proud of the organisation and my small role. I joined as I identified with the mission. The enormity of what I am doing on a global scale pushes me to continue to do it even though the team is completely stretched.

I like the moral dimension of contributing to something useful and I identify with the powerful and motivating mission of protecting and helping. I feel a human connection with each person we have helped.

However, some workers reported over-engagement, described as being exceedingly involved in their activities and feeling unable to withdraw from work. This was perceived to be directly related to the need to fulfil humanitarian objectives and is reflected in 'people are super engaged with a strong belief in the mission':

I plan to say 'no' to requests, but I never do, because I want to help the organisation and all beneficiaries. I find the responsibility huge and so it is very difficult to switch off. If there are delays on a decision the recipients can suffer.

We are over engaged - perhaps because of the mission. I know that my passion feeds into the organisational demands and expectations.

\section{Work overload}

Work overload was one of the strongest themes across all of the interviews and manifested itself as a significant source of stress. Managing your workload 'is a hot potato, there are never enough resources'. Some employees felt that there was also an unfair distribution of resources:

We could still certainly double the staff on our team. If you compare our workload to other divisions we are suffering. We don't have enough resources in our unit. 
Some employees commented that they were expected to undertake unrealistic or unmanageable workloads that had a number of major consequences:

I am exhausted each day and feel life is a marathon. I need the weekends to recover rather than a time to enjoy. This causes a clash with my family commitments.

It doesn't matter what day it is, Monday or Saturday or a holiday, the minute I wake up it is work. I even dream about work. We are really balancing on the edge. It's difficult to solve this because people are stretched so far and there's nothing to lean on and no time and resources to spend or invest in resolving some of these issues.

The internal dilemma facing employees was summed up well by one participant: ' $[w]$ e are doing the right thing. My family say I love and I hate my job. I love the work and what it means and I hate the amount of work I have to do to achieve the results'. The ramifications of work overload were clearly linked to stress, but there were also connections to performance, such as: 'I never have time to review my work and read the guidelines'. Employees feeling under excessive pressure were more likely to be dissatisfied with their job, seek new employment, and report negative effects on their mental and physical health.

\section{Managing work-life boundaries}

Employees underlined the need to work long, unsocial, and irregular hours to meet the demands placed on them and the negative implications of this for worklife balance:

You work non-stop during the day and know that you have work at night. I can't set boundaries.

I often don't manage my workload. I leave the office to take care of the children and once they are in bed I go back to work.

Many employees referred to the difficulty in balancing their personal and professional lives, and for some work became all-encompassing:

I don't manage my workload. My priority is my job. I had a discussion with a counsellor as I had reached an emotional point where I realised that nothing but my job mattered. I have to learn to have a balance.

Work becomes one's life when family and friends are not around.

Some employees felt more responsible for maintaining an acceptable degree of separation between the work and home domains. The setting of boundaries helped them to cope and made them more realistic about their own performance potential. This is illustrated by the following two quotes: 
There is lots of talk about work-life boundaries but it is really me who has to set them. I can only do my best, and that has got to be good enough.

I really need to step back and say your urgency is not my urgency. I have rights too. I do set boundaries for others and myself. It helps me cope.

\section{Social support}

\section{Managers}

Managers' were seen to be helping employees deal with stress and work overload and were an 'incredible source of support'. Two employees expressed their experiences of support as follows:

When I have a nurturing boss who cares, who sees me burning out, who tells me to calm down, someone who is a mirror, an intellectual partner. When I feel alone this helps me a lot and I go the extra mile. This makes a huge difference.

I get a great deal of support from my manager. My manager is motivational and enthusiastic, yet sets high standards for himself and the rest of the team, but in such a positive way.

Several employees noted, though, that they 'handpick whom they trust'. The amount of support they received was largely dependent on the qualities of their manager. One study participant emphasised that: 'I am so careful about who I talk to as I have learnt to have a deep fear of being judged and of never being enough'. A number of participants suggested that managers might improve their skillset by attending training in communication, leadership, and management. This was especially true if managers had been selected more on the basis of their specialised knowledge than their ability to manage people. A typical response in this regard was: '[w]e have specialists who run teams but they are not trained managers'.

When managerial relationships were not perceived as supportive it contributed to work stress and negative health outcomes:

I have no voice and am fearful of asking for help. I have been shot down, had doors closed on me. I have a sense of insecurity. I fear retaliation and am anxious to voice my opinion.

\section{Team and colleague support}

Almost all of the respondents underscored the importance of maintaining healthy teams based on networks of relationships. Some expressed a sense of joy, fulfilment, and loyalty due to working as a team and being supported by colleagues. Supportive relationships were key to managing stress at work and allowed employees to find meaning in what they do:

I enjoy positive reinforcement from my peers. It is great when they and the people on the ground give me feedback and recognition that we are making a difference. 
The team is really everything and maintaining a cooperative culture really essential. Strong and cohesive teams do exist and do provide motivation, trust, and a challenging and positive environment. We have a willingness to share the load.

Several employees drew attention to the role played by trust in this respect:

If people can't depend on each other and work together as professionals they fail. Forming mutually trusting relationships of support and confidence is not always obvious.

There is a lot of trust in the team, a lot of team-building, so it is a pleasure to go to work and makes it manageable.

A supportive network generated a secure sense of connection with others. This positive resource served as a buffer against the costs of anxiety and lessened individual perceptions of stress. Threats to the mental health of employees were found in the underlying tensions and interpersonal conflicts that arose with colleagues and managers. Other reported consequences of such challenges and low interpersonal support included culture shock, isolation, loneliness, and physical discomfort.

\section{Health outcomes}

There was evidence of work causing chronic stress among some employees. They strongly linked stress, work overload, and an inability to withdraw from the demands of work with negative mental and physical health. Distress was reported as taking the form of anxiety, burnout, depression, and/or a deterioration in physical health, and manifested in absenteeism. These stress-related physical illnesses were sometimes serious enough to warrant hospitalisation. Some employees had requested coaching or counselling to deal with mental health issues. Three employees said that they had an emotional breakdown during the previous year as a result of work pressure. For instance:

I can't sleep and feel absolute fear at the stress that comes over me at times. I have this work anxiety every day, trying to cope with everything. There are a lot of people ill on our team, on sick leave, in hospital, and I would say [it is] stress-related.

I am exhausted each day. I feel unable to control or limit my job. I put in effort and then get many demands until I feel like I am emotionally drowning.

\section{Discussion}

Through a close examination of individual aid worker experiences, this study produced rich, thematic descriptions that provided insights into the lived experience of work-related stress. These were specific and relevant to the humanitarian realm, central to the success of this study. Some factors captured in this qualitative assessment, 
such as the rewards of altruism or the emergency setting, might have gone unidentified in generic (stress) questionnaire research (Mazzola, Schonfeld, and Spector, 20I I).

Participants generally felt positive about and rewarded by their contribution to the organisation, but experienced high levels of stress in a demanding context. They recognised the external pressures and complexities facing humanitarian organisations trying to help those in need. Identifying with these altruistic ambitions, many operated in a constant state of urgency to meet deadlines. Many employees perceived the need to respond to changing circumstances and pressing demands as stressful and better planning was suggested in order to move away from an emergency culture. Other research confirms that the work environment of humanitarian aid workers is constantly changing, time pressured, and unpredictable (Majchrzak, Jarvenpaa, and Hollingshead, 2007; Yanay, Benjamin, and Yamin, 20I ; Blanchet and Michinov, 20I4).

Strong identification with the mission, and the responsibility felt to help those in need, resulted in ceaselessly high engagement and a perceived inability to withdraw from work. Commitment is an important part of engagement, an optimal state where employees are intrinsically motivated and have high energy levels to enjoy work challenges. However, at the extreme, over-commitment can increase the chance of strain reactions (van Vegchel et al., 2005). Overcommitted persons repeatedly overtax their own resources and, thus, precipitate exhaustion in the long run (Joksimovic et al., I999). It seems possible that, on the one hand, commitment is a motivational factor promoting work engagement, but, on the other hand, too much commitment is a risk factor associated with negative health outcomes and stress (Feldt et al., 20I3). Varying levels of work engagement might actually be more beneficial than persistently high levels of work engagement (George, 20I0), which can lead to a loss of energy or work-family conflict (Halbesleben, 20II) and even more demands (Sonnentag, Binnewies, and Mojza, 20I0). This study sheds light on the motivations behind the inability to withdraw from work and excessive striving, and may inform interventions to promote healthier coping responses to external demands.

These findings suggest that much of the stress and related anxiety among HAWs is due to the volume and complexity of the work required to succeed. Work overload, constraints imposed by the external environment, such as those pertaining to funding and resources, and a collective internal drive to meet humanitarian needs have all contributed to the development of a culture where insufficient boundaries are set for what people are reasonably expected (and expect themselves) to do. Many employees seemed unable or struggled to achieve work-life balance. In an Australian study, work overload was observed to be the strongest predictor of full-time employees' work-life conflict (Skinner and Pocock, 2008). The participants in this evaluation also linked work overload and work-life conflict with negative health outcomes such as anxiety and burnout. Bakker and Demerouti (2007) point out that the health impairment process occurs where high demands exceed psychological and physical resources, and consequently result in ill-health and negative organisational outcomes. 
The same drive to meet humanitarian needs is also perceived as an important form of reward, and many derive meaning from their work because of the overall impact the organisation has on the populations it serves. The social or altruistic reward of serving others is not currently included in theoretical stress models. This may be a useful practical and theoretical addition to frameworks, including the one that sees effort and reward imbalance (Siegrist, 1996) as a predictor of strain in human service professionals. As specific rewards may have specific effects, researchers note the importance of differentiating between different types of rewards (van Vegchel et al., 2002; Dragano et al., 2003).

The existence of supportive relationships and collaboration within teams and with managers was seen as vital to employee well-being. Supportive relationships at work were perceived as helping employees manage their workload and work-life balance more effectively. Employee reactions to psychosocial hazards were also directly influenced by the quality of their inter-personal relationships at work. Respondents reported feeling more valued, understood, and motivated, as well as less stressed and fearful, when sound collegial relationships and leadership were in place. The review by Mazzola, Schonfeld, and Spector (20I I) identified the most prevalent stressor in the workplace as interpersonal conflict. Other works confirm that the relations between leaders and their employees are associated with employee stress and affective well-being (Skakon et al., 20IO). In the present study perceived lack of trust was an important component of the connection between work relationships and increased stress. However, further research is needed to advance understanding of the processes behind such a linkage.

\section{Conclusion}

These findings suggest that organisation-level interventions are warranted, involving the development of leadership skills in the provision of day-to-day support to employees. Participants expressed a need for more consistency in people management skills. Improvements in the quality of relationships with managers, especially building trust in leadership (Liu, Siu, and Shi, 20IO), could enhance employee well-being. Interventions could also improve work design, organisation, and management to better team working and control over work, promote informal social support, evaluate and plan for work demands and staffing in an emergency context, avoid ambiguity in job security, and create adaptable work schedules to achieve work-life balance. Employees could increase (through training) their awareness, knowledge, skills, and coping resources to navigate stressful conditions more effectively. Conditions relevant to this study include interpersonal relationships (between colleagues and with supervisors), over-engagement, work overload, and boundary management in an emergency culture.

The key strengths of this study are to be found in its successful examination of work-related stress among a hitherto neglected occupational group (Kidd, Scharf, 
and Veazie, I996). The interview-based data collection methodology allowed for full and frank sharing of experiences with the researchers, and the relatively large sample size permitted a qualitative interview-based evaluation that ensured data collection could end only when full thematic saturation had been achieved.

Nevertheless, the study also has a couple of key limitations that need to be considered when interpreting the findings. First, interviewees had to rely on retrospective recollections of fieldwork to answer some of the questions. Although most participants travel regularly to other countries ('the field'), this should be considered when comparing the results with those of other or future assessments that involve participants who may be operating in the field at the time of appraisal. Second, it is possible that the experiences of work-related stress expressed here are particular to the organisation under review rather than being indicative of humanitarian aid work in general; further research is required to confirm these findings on a sectorwide level.

In summation, this study generated a rich narrative-based bank of knowledge concerning organisational, as opposed to operational, work-related stress among HAWs. It found that an emergency culture coupled with strong identification with the organisation and humanitarian goals was related to work overload and work-life imbalance. Negative health outcomes, such as anxiety, were common. The study was exploratory, though, and the perceived causes should not be viewed in terms of epidemiological causal relationships, but rather as pointers to guide the development of interventions in such work settings. Future work should consider how to improve management practices, given their fundamental relation with perceived work stress. Finally, these qualitative findings can provide a basis for the development of a sector-specific, quantitative risk assessment tool.

\section{Acknowledgements}

Liza Jachens and Roslyn Thomas received funding from the study's host organisation, which wishes to remain anonymous.

\section{Correspondence}

Liza Jachens, Psychology, Sociology and Professional Counseling Faculty, Webster University, Route de Collex I5, CH-I293 Bellevue, Switzerland.

Telephone: +4I 22959 8000; e-mail: jachens@webster.ch

\section{References}

Ager, A., E. Pasha, G. Yu, T. Duke, C. Eriksson, and B.L. Cardozo (2012) 'Stress, mental health, and burnout in national humanitarian aid workers in Gulu, northern Uganda'. Journal of Traumatic Stress. 25(6). pp. 713-720. 
Bakker, A.B. and E. Demerouti (2007) 'The job demands-resources model: state of the art'. Journal of Managerial Psychology. 22 (3). pp. 309-328.

Beiske, B. (2002) Research Methods: Uses and Limitations of Questionnaires, Interviews, and Case Studies. GRIN Verlag, Munich.

Bernard, H.R. (2012) Social Research Methods: Qualitative and Quantitative Approaches. SAGE Publications, Newbury Park, CA.

Bhui, K., S. Dinos, M. Galant-Miecznikowska, B. de Jongh, and S. Stansfeld (2016) 'Perceptions of work stress causes and effective interventions in employees working in public, private and nongovernmental organisations: a qualitative study'. BJPsych Bulletin. 40(6). pp. 318-325.

Blanchet, C. and E. Michinov (20I4) 'Relationships between stress, social support and transactive memory among humanitarian aid workers'. International Journal of Emergency Management. Io (3-4). pp. 259-275.

Blase, J.J. (I986) 'A qualitative analysis of sources of teacher stress: consequences for performance'. American Educational Research Journal. 23(I). pp. I3-40.

Bonde, J.P.E. (2008) 'Psychosocial factors at work and risk of depression: a systematic review of the epidemiological evidence'. Occupational and Environmental Medicine. 65(7). pp. 438-445.

Braun, V. and V. Clarke (2006) 'Using thematic analysis in psychology'. Qualitative Research in Psychology. 3(2). pp. 77-IOI.

Brough, P. (2002) 'Female police officers' work experiences, job satisfaction and psychological wellbeing'. Psychology of Women Section Review. 4. pp. 3-I5.

Brough, P. (2004) 'Comparing the influence of traumatic and organizational stressors on the psychological health of police, fire, and ambulance officers'. International Journal of Stress Management. I I (3). pp. 227-244.

Brough, P. and A. Biggs (20I5) 'Job demands x job control interaction effects: do occupation-specific job demands increase their occurrence?'. Stress and Health. 3I(2). pp. I38-I 49.

Brown, J., J. Fielding, and J. Grover (I999) 'Distinguishing traumatic, vicarious and routine operational stressor exposure and attendant adverse consequences in a sample of police officers'. Work and Stress. I3 (4). pp. 3I2-325.

Cardozo, B.L. et al. (2005) 'The mental health of expatriate and Kosovar Albanian humanitarian aid workers'. Disasters. 29(2). pp. I52-I70.

Connorton, E., M.J. Perry, D. Hemenway, and M. Miller (2011) 'Occupational trauma and mental illness - combat, peacekeeping, or relief work and the national co-morbidity survey replication'. Journal of Occupational and Environmental Medicine. 53(I2). pp. I360-I363.

Connorton, E., M.J. Perry, D. Hemenway, and M. Miller (2012) 'Humanitarian relief workers and trauma-related mental illness'. Epidemiologic Reviews. 34(I). pp. I45-I55.

Cox, T. and A. Griffiths (2010) 'Work-related stress: a theoretical perspective'. In S. Leka and J. Houdmont (eds.) Occupational Health Psychology. Wiley-Blackwell, Oxford. pp. 3 I-56.

Creswell, J.W., V.L.P. Clark, M.L. Gutmann, and W.E. Hanson (2003) 'Advanced mixed methods research designs'. In A. Tashakkori and C. Teddlie (eds.) Handbook of Mixed Methods in Social and Behavioral Research. SAGE Publications, Thousand Oaks, CA. pp. 209-240.

Dragano, N., O. von dem Knesebeck, A. Rodel, and J. Siegrist (2003) 'Psychosocial work stress and musculo-skeletal disorders: significance for prevention'. Journal of Public Health. I I (3). pp. I96-207.

Durand, M. (2015) 'The OECD better life initiative: how's life? and the measurement of well-being'. Review of Income and Wealth. 6I(I). pp. 4-I7.

Ehrenreich, J.H. and T.L. Elliott (2004) 'Managing stress in humanitarian aid workers: a survey of humanitarian aid agencies' psychosocial training and support of staff'. Peace and Conflict: Journal of Peace Psychology. Io(I). pp. 53-66.

Feldt, T. et al. (2013) 'Long-term patterns of effort-reward imbalance and over-commitment: investigating occupational well-being and recovery experiences as outcomes'. Work and Stress. 27(I). pp. 64-87. 
George, J.M. (2010) 'More engagement is not necessarily better: the benefits of fluctuation levels of engagement'. In S. L. Albrecht and E. Corporation (eds.) Handbook of Employee Engagement: Perspectives, Issues, Research and Practice. Edward Elgar, Cheltenham. pp. 253-263.

Halbesleben, J.R.B. (20II) 'The consequences of engagement: the good, the bad, and the ugly'. European Journal of Work and Organizational Psychology. 20(I). pp. 68-73.

Hart, P.M. and P. Cotton (2003) 'Conventional wisdom is often misleading: police stress within an organisational health framework'. In M.F. Dollard, A.H. Winefield, and H.R. Winefield (eds.) Occupational Stress in the Service Professions. Taylor and Francis, London. pp. I03-I4I.

Houdmont, J. (2017) 'Stressors in police work and their consequences'. In R. Burke (ed.) Stress in Policing: Sources, Consequences, and Interventions. Routledge, London. pp. 5I-65.

Jachens, L., J. Houdmont, and R. Thomas (20I6) 'Effort-reward imbalance and heavy alcohol consumption among humanitarian aid workers'. Journal of Studies on Alcohol and Drugs. 77(6). pp. 904-9I3.

Joksimovic, L. et al. (1999) 'Overcommitment predicts restenosis after coronary angioplasty in cardiac patients'. International Journal of Behavioral Medicine. 6(4). pp. 356-369.

Kidd, P., T. Scharf, and M. Veazie (1996) 'Linking stress and injury in the farming environment: a secondary analysis of qualitative data'. Health Education and Behavior. 23(2). pp. 224-237.

Lindsay, V., W.B. Taylor, and K. Shelley (2008) 'Alcohol and the police: an empirical examination of a widely-held assumption'. Policing. 3I (4). pp. 596-609.

Liu, J., O.L. Siu, and K. Shi (20I0) 'Transformational leadership and employee well-being: the mediating role of trust in the leader and self-efficacy'. Applied Psychology. 59(3). pp. 454-479.

Majchrzak, A., S.L. Jarvenpaa, and A.B. Hollingshead (2007) 'Coordinating expertise among emergent groups responding to disasters'. Organization Science. I8(I). pp. I47-I6I.

Malterud, K. (200I) 'Qualitative research: standards, challenges, and guidelines'. The Lancet. 358 (9280). pp. $483-488$.

Manning, D. and A. Preston (2003) 'Organizational stress: focusing on ways to minimize distress'. College and University Professional Association for Human Resources Journal. 54(2). pp. I5-I8.

Mazzola, J.J., I.S. Schonfeld, and P.E. Spector (20II) 'What qualitative research has taught us about occupational stress'. Stress and Health. 27(2). pp. 93-IIO.

Narayanan, L., S. Menon, and P. Spector (I999) 'A cross-cultural comparison of job stressors and reactions among employees holding comparable jobs in two countries'. International Journal of Stress Management. 6(3). pp. 197-212.

Netterstrøm, B. et al. (2008) 'The relation between work-related psychosocial factors and the development of depression'. Epidemiologic Reviews. 30(I). pp. II8-I32.

Noblet, A., S.T. Teo, J. McWilliams, and J.J. Rodwell (2005) 'Which work characteristics predict employee outcomes for the public-sector employee? An examination of generic and occupationspecific characteristics'. International Journal of Human Resource Management. I6(8). pp. I4I5-I430.

Pryjmachuk, S. and D.A. Richards (2007) 'Mental health nursing students differ from other nursing students: some observations from a study on stress and coping'. International Journal of Mental Health Nursing. I6(6). pp. 390-402.

Ritchie, J., J. Lewis, C.M. Nicholls, and R. Ormston (2013) Qualitative Research Practice: A Guide for Social Science Students and Researchers. SAGE Publications, London.

Schonfeld, I.S. and J.J. Mazzola (20I2) 'Strengths and limitations of qualitative approaches to research in occupational health psychology'. In R.R. Sinclair, M. Wang, and L.E. Tetrick (eds.) Research Methods in Occupational Health Psychology: Measurement, Design and Data Analysis. Routledge, London. pp. 268-289.

Schütte, S. et al. (20I4) 'Psychosocial working conditions and psychological well-being among employees in 34 European countries'. International Archives of Occupational and Environmental Health. $87(8)$. pp. $897-907$. 
Shane, J.M (2010) 'Organizational stressors and police performance'. Journal of Criminal Justice. 38 (4). pp. $807-8 \mathrm{I} 8$.

Siegrist, J. (I996) 'Adverse health effects of high-effort/low-reward conditions'. Journal of Occupational Health Psychology. I(I). pp. 27-4I.

Skakon, J., K. Nielsen, V. Borg, and J. Guzman (20I0) 'Are leaders' well-being, behaviours and style associated with the affective well-being of their employees? A systematic review of three decades of research'. Work and Stress. 24(2). pp. I07-I39.

Skinner, N. and B. Pocock (2008) 'Work-life conflict: is work time or work overload more important?'. Asia Pacific Journal of Human Resources. 46(3). pp. 303-3I5.

Sonnentag, S., C. Binnewies, and E.J. Mojza (20I0) 'Staying well and engaged when demands are high: the role of psychological detachment'. Journal of Applied Psychology. 95(5). pp. 965-976.

Spector, P.E. and S. Pindek (2015) 'The future of research methods in work and occupational health psychology'. Applied Psychology. 65(2). pp. 4I2-43I.

Stansfeld, S. and B. Candy (2006) 'Psychosocial work environment and mental health-a metaanalytic review'. Scandinavian Journal of Work, Environment and Health. 32 (6). pp. 443-462.

Starks, H. and S.B. Trinidad (2007) 'Choose your method: a comparison of phenomenology, discourse analysis, and grounded theory'. Qualitative Health Research. I7(IO). pp. I372-I380.

Sverke, M., J. Hellgren, and K. Näswall (2002) 'No security: a meta-analysis and review of job insecurity and its consequences'. Journal of Occupational Health Psychology. 7(3). pp. 242-264.

van Vegchel, N., J. de Jonge, A. Bakker, and W. Schaufeli (2002) 'Testing global and specific indicators of rewards in the effort-reward imbalance model: does it make any difference?'. European Journal of Work and Organizational Psychology. II(4). pp. 403-42I.

van Vegchel, N., J. de Jonge, H. Bosma, and W. Schaufeli (2005) 'Reviewing the effort-reward imbalance model: drawing up the balance of 45 empirical studies'. Social Science and Medicine. $60(5)$. pp. III7-II3I.

Welton-Mitchell, C.E. (20I3) UNHCR'S Mental Health and Psychosocial Support for Staff. Policy Development and Evaluation Service, United Nations High Commissioner for Refugees, Geneva.

Yanay, U., S. Benjamin, and H.G. Yamin (20I I) 'Networking emergency teams in Jerusalem'. Disasters. 35(I). pp. I83-I99. 